\title{
Augmented Reality as a Research Tool, for the Knowledge and Enhancement of Cultural Heritage
}

\author{
Marco Canciani \\ Giovanna Spadafora \\ Mauro Saccone \\ Antonio Camassa
}

\section{Abstract}

Starting from a reflection on the new role of digital technology in this pandemic situation, and particularly the role of AR for Cultural Heritage, this paper presents two AR applications. The first is used to share the analyses carried out on the Pantheon surveys realized between the seventeenth and nineteenth centuries. The second is about the illusionistic dome in the Church of Sant'Ignazio in Rome, realized by Andrea Pozzo. These two applications can display three-dimensional models superimposed onto images and original drawings, and also two-dimensional contents: the results of graphical analysis carried out on digital copies. The final aim of this ongoing research is to develop some AR multimedia content, linked to semantic concepts.

\section{Keywords}

augmented reality, cultural heritage, geometric analysis, 3D survey.

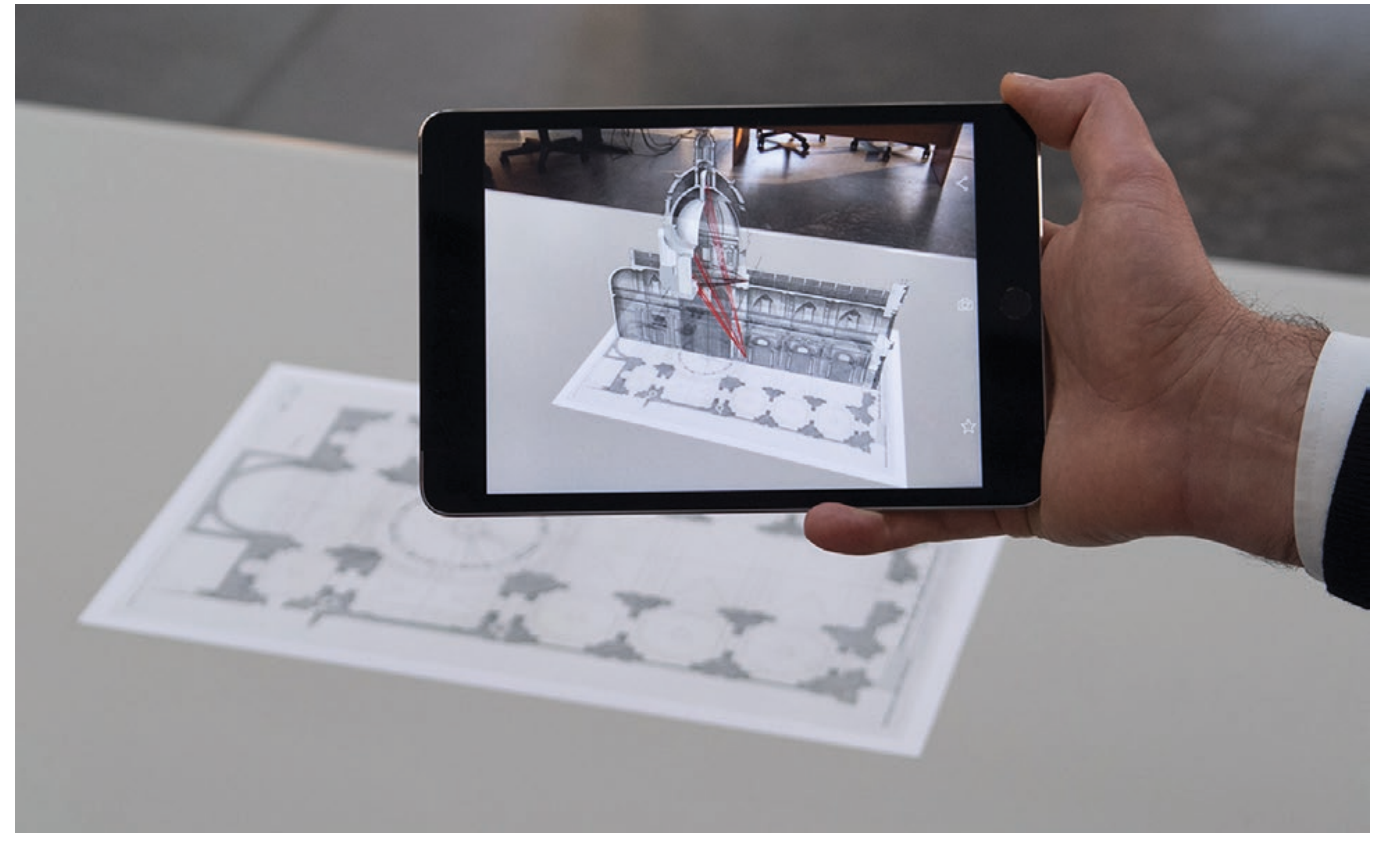




\section{Premise}

This last year, with the restrictions due to the Covid-19 pandemic, the growth of digital technologies, applied to activities related to cultural heritage but which cannot be accessed physically, have accelerated in an unprecedented manner, thus generating innumerable spawning of network applications, a kind of "digital golden rush" [Concas 2021 , p. 15]. A profound evaluation and reformulation of digital methodologies and technologies are thus deemed necessary, for they have led to a turning point, a kind of "destructive innovation" [Santamaria 202 I].

Virtual, mixed, and augmented reality have all become common terms in recent years. However, the relationship between real and virtual is not only of interest at present. Since the 1990s, Tomás Maldonado initiated reflections on the theme of the relationship between the real and the virtual according to which a (real) painting prefigures a space of the (virtual) pictorial scene, in a relationship that transcends the boundaries between space and time [Maldonado 1995, p. 162]. In this context, some examples are the eighteenth-century views of the historic center of Dresden by Bernardo Bellotto, in which the space depicted in the (virtual) painting is used as a reference model for the post-war reconstructions (real) of the old city, destroyed in the 1945 allied bombings. The same space-time relationship is evidenced in a 2016 installation, where the view of Dresden from Elba's right bank depicted in a 1748 painting (virtual) by the Venetian painter is viewed within an empty frame (real) [Dal Pozzolo 202 I, p. | 45].

Augmented reality certainly represents the most appropriate digital tool to permit the observer to move within a hybrid space, that is physical and virtual. Already in 1995 [Milgram et al. 1995], Augment Reality (AR) was situated within a space defined as a Virtuality-Reality Continuum, and delimited by two extremes, the real and the virtual world. According to the definition by Nofal [Nofal et al. 2017], AR moves within a hybrid space (called Phygital, a fusing of the terms physical and digital), where the boundaries between physical and virtual space are not necessarily clear or defined, thus delineating various degrees of AR and varying uses of virtual contents. These can be described according to three typologies:

I) the first type, multimedia, where information related to an object, physical and real, are connected through various media (texts, images, data);

2) the second type, hybrid, to the real object, a two-dimensional print or drawing, are connected data and models, which may themselves be two or three dimensional;

3) the third type, three-dimensional, to the real object, that is the physical space enveloping the observer, data and virtual 3D objects are superimposed. This represents the most advanced level in the use of $A R$.

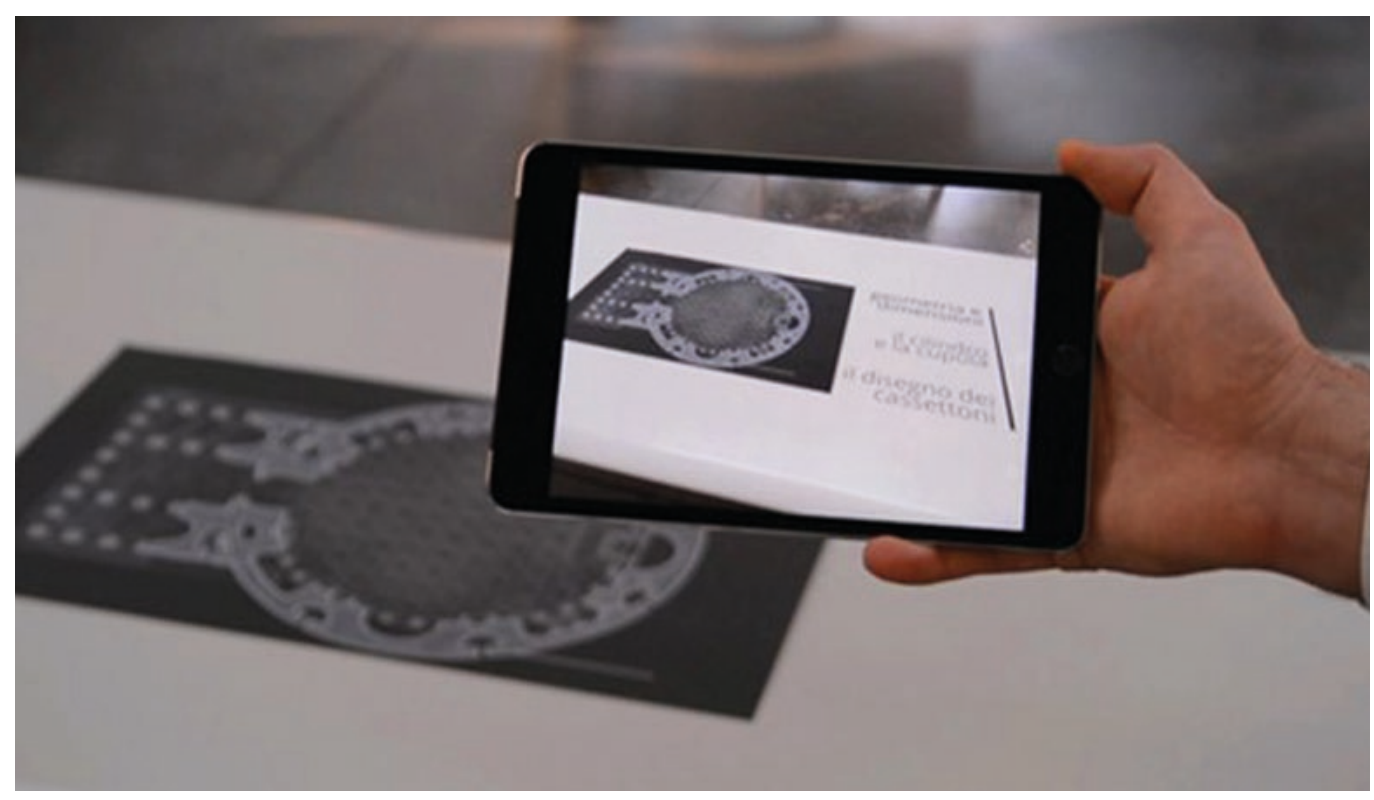




\section{Introduction to AR Applications}

The applications described in this article are at a stage prior to the final aims of the research, but present interesting results with potential developments yet to be explored. These applications integrate the usual display mode of three-dimensional models superimposed onto images and drawings with two-dimensional contents, that is to say, the results of graphical analysis carried out on digital copies. The fundamental issues in these types of applications are related to the need to be able to identify a rational selection and synthesis of the scientific contents to be displayed which, though necessary, given the effectiveness and distinctness of the means of communication used, must not compromise the scientific result. The project [I], whose initial report is presented here, addresses these issues by identifying in each of the themes presented, the narrative lines of the contents, allowing different levels of detailed studies, through a sharing of information that is gradually more complex, to meet the diverse interests of distinct users [2].

From a technical point of view, the applications were developed on a platform that simplifies the AR experience project, is compatible with all kinds of devices [3], and guarantees sufficient accuracy in the overlap of various levels of information. Its versatility has allowed an ad hoc development, addressing the categories of possible users and the sites where the AR experience may be employed. The two applications, described below in detail, refer to two different contexts but share the same objectives: to convey unusual items of knowledge, perhaps not easily understood immediately, but that aim to show how the drawing and the use of AR technologies can reveal the geometries underlying the apparent forms, and also bring them to the attention of the general public and stimulate the more inquisitive ones to research further, in more appropriate locations.

\section{AR-Pantheon: Survey and Drawings}

The objective of the first application was to use AR to share the analyses carried out on the Pantheon [4] surveys realized between the seventeenth and nineteenth centuries, in particular the studies carried out by the pensionnaires of the Académie des Beaux Arts in Paris and by the students of the Academy of San Luca in Rome. An analysis of the survey drawings tells us how, over time, the architects looked to antiquity, allowing them to consolidate their knowledge on the construction and conservation history of the monument. Consulting the original drawings in the archives of the aforementioned Academies [AABA] [Marconi 1974] made it possible to closely analyze the documents to identify the marks relating to the construction lines and the holes of the compass points.

The 3D survey of the Pantheon, achieved through the use of integrated systems (photogrammetry and laser scanner), made it possible to carry out an accurate comparison between the archival drawings and drawings of their present state.

The results of the analyses and of the superpositions were processed so they could be displayed by the AR application (see note 3), which uses marker-based tracking technology [Bekele 20।8, p. 5]. The application was realized with a dual purpose: on the one hand, the possible use in an exhibition of the drawings of the Pantheon, on the other, directly in the archive, to show the analyses carried out, superimposed over the original drawings. The application can also highlight the different interpretations of the geometry of the Pantheon and the transformations undergone in its transition from an ancient monument to a church.
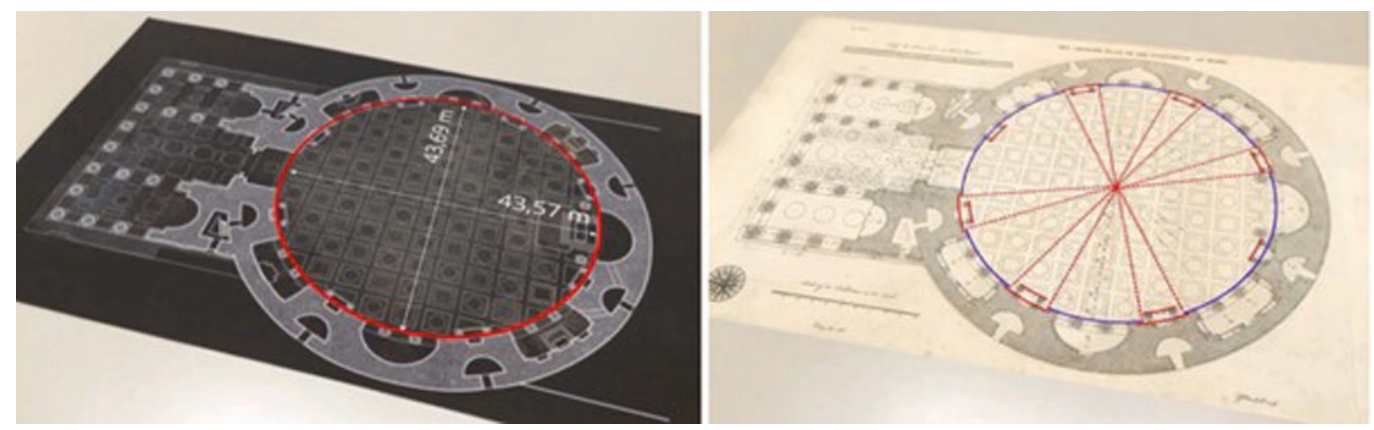
When the drawings are displayed, AR side menus (fig. I) introduce the main items, such as the geometry and size of the Pantheon dome, to compare how the different authors of the various survey drawings interpreted them (fig. 2).

Thanks to the use of geometric elements (the circumferences, axes, tangents, etc.) and three-dimensional models (the cylinder and the sphere) superimposed on the plans and sections, our augmented reality application summarizes - by relating the drawings in space, the plans (virtual) and the sections (real) - the different analyses of the monument that the architects of the past carried out.

\section{Andrea Pozzo Augmented Perspective}

The second application refers to the illusionistic dome in the Church of Sant'lgnazio in Rome, the work of Andrea Pozzo (I 642- I709) [5].

The development of an AR application on this theme began with a consideration of the spatial location of the canvas depicting the illusionistic dome (fig. 3) horizontally situated 32 meters above ground, at the intersection between the nave and the transept of the church of Sant'Ignazio in Rome. The canvas, simulating a real dome in perspective, is correctly visible from a preferential point of view indicated on the ground by a marble disc, which allows visitors to comprehend the perceptive artifice. The technique used (tempera), over time, has developed a blackening of the pictorial surface [6] so that one cannot appreciate it as it would have been in 1685, the year it was installed in the cross-vault. So an AR application was developed, with the intent to convey not just the wealth of details of the painting but above all the perspective scheme that allowed Pozzo to compose the illusionistic dome. Thanks to a simple setup of two display panels (fig. 3), the application allows an augmented interaction with a scale reproduction of the painting.

The application is divided into three sections: users can choose the content according to their interests on the subject selecting different levels of information detail.

In the section 'artistic historical research' one can compare different works of illusionistic domes ascribable to Pozzo, collated in the different phases of the historical-archival study. Thereby offering the possibility of partially superimposing over the marker, depicting the painting, the drawings and sketches of other illusionistic domes by Andrea Pozzo, compared instantaneously thanks to the virtual space of the AR.

In the 'surveys' section, it is possible to view, aligned with the marker, the high-resolution photo, to analyze the pictorial consistencies of the architectural elements of the work down to the smallest details, which are otherwise invisible when viewing the original, given the height at which the canvas is placed.

The section 'geometric analyses' contains the graphic elaborations carried out on the painting, beginning with the study of the two methods that Andrea Pozzo describes in the two volumes of

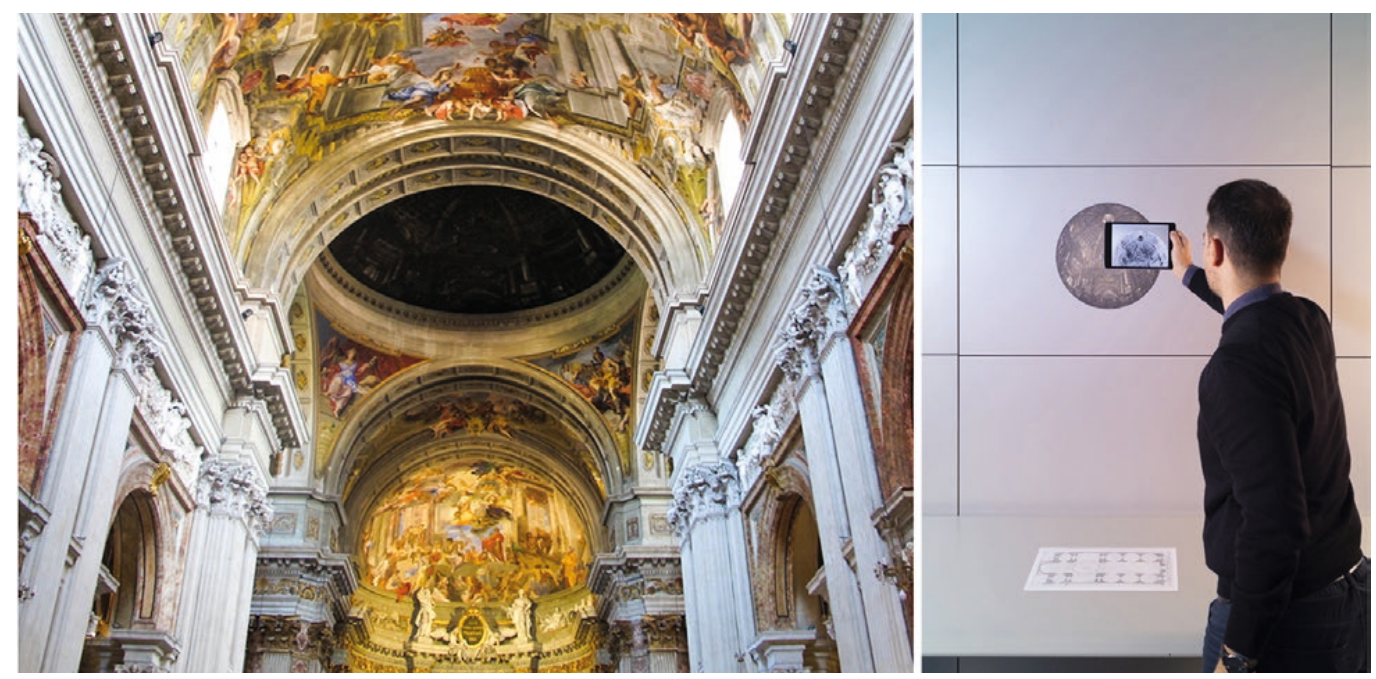


his treatise Perspectiva pictorum et architectorum (Vol. I 1693,Vol. II 1700). Several layers gradually are superimposed over the marker, evidencing the perspective restitution operations carried out to retrace the architectural section from the perspective drawing.

With the application, one can visualize a section of the model of the church and relate it to the plan (fig. in front page). The aim of the model is twofold, to represent the church with the virtual reconstruction of the dome designed by Pozzo and at the same time show the perspective method underlying the same restitution by retracing, in reverse, Andrea Pozzo's modus expeditissimus.

\section{Conclusions}

These two case studies show how we have used AR to share the analyses carried out on drawings and canvas. In the future, this kind of application should integrate databases organized according to semantic structures [Canciani 2020], which can connect related research fields. Our aim is to develop on-site AR applications, using markerless tracking, to introduce 3D models as well as two-dimensional contents surrounding the users.

\section{Notes}

[I] Working on the project is the research team of the Department of Architecture (Roma Tre) consisting of M. Canciani, G. Spadafora, M. Saccone, A. Camassa, in collaboration with the ENEA research team coordinated by M. Mongelli.

[2] It is understood that the level of detail proposed in the project is consistent with the methods designed for these two particular AR applications.

[3] The commercial application used is blippARß.

[4] Selected were some of the results of the doctoral research: Disegnare il Pantheon. La pratica del rilievo nell'insegnamento accademico del XIX secolo e nel disegno digitale contemporaneo presented by Mauro Saccone in the XIX cycle of Architectural Doctorate: innovation and heritage (tutor Marco Canciani).

[5] The application presented here draws on some results of the doctoral research, currently being completed, "congiugnere il finto col vero" - Geometria e architettura nella finta cupola di Andrea Pozzo a Roma, presented by Antonio Camassa, XXXIII cycle of the Architectural Doctorate: innovation and heritage (tutor Giovanna Spadafora).

[6] As the early 18th century, the illusionistic dome was not visible, as reported in [Montalto 1962].

\section{References}

Bekele Mafkereseb K., Pierdicca Roberto, Frontoni Emanuele, Malinverni Eva S., Gain James (20 I 8). A survey of augmented, virtual, and mixed reality for cultural heritage. In Journal on Computing and Cultural Heritage (JOCCH), I I.2, pp. I-36.

Canciani Marco, Saccone Mauro (20I I). The use of 3D models in integrated survey: the church of St. Thomas ofVillanova in Castel Gandolfo. In International Archives of Photogrammetry, Remote Sensing and Spatial Information Sciences vol. 38.5M I 6, pp. 59 I-597.

Canciani Marco Saccone Mauro, Spadafora Giovanna, Gallia Arturo, Masetti Carla (2020). Modelli 3D e dati GIS: una loro integrazione per lo studio e la valorizzazione dei beni culturali. In ARCHEOMATICA, XII (2), pp. I 8-23.

Chevalley Giovanni (1924). Elementi di tecnica dell'architettura: materiali da costruzioni e grosse strutture. Torino: Pasta.

Concas Andrea (2020). L'arte post Coronavirus. Ripartire con il digitale: le strategie per i professionisti dell'arte. Segrate: ed. Piemme.

Dal Pozzolo Luca (202 I). Il patrimonio culturale tra memoria, lockdown e futuro. Milano: Editrice Bibliografica.

Maldonado Tomás (1995). Reale e virtuale. Milano: Feltrinelli.

Marconi Paolo (1974). I disegni di architettura dell'Archivio storico dell'Accademia di San Luca.Voll. I e II. Roma: De Luca Editori.

Milgram Paul, Takemura Haruo, Utsumi Akira, Kishino Fumio (1995). Augmented Reality: A class of displays on the realityvirtuality continuum. In Proceedings of SPIE 2351, Telemanipulator and Telepresence Technologies, pp. 282-292.

Montalto Lina (1962). La storia della finta cupola di S. Ignazio. In Capitolium, 6, pp. 393-404.

Nofal Eslam, Reffat M. Rabee,Van de Moere Andrew (2017). Phygital heritage: An approach for heritage communication. In Beck Dennis. et al., Immersive Learning Research Network Conference. Berlin: Springer, pp. 220-229.

Santamaria, Martina (202I ). Il digitale come disruptive innovation nell'ecosistema culturale: un nuovo paradigma in reazione all'emergenza COVID-19,Tesi (con Marco Romano) nel Master in Editoria, Giornalismo e Management culturale, La Sapienza Università di Roma.

\section{Authors}

Marco Canciani, Dept. of Architecture, Università RomaTre, marco.canciani@uniroma3.it

Giovanna Spadafora, Dept. of Architecture, Università RomaTre, giovanna.spadafora@uniroma3.it

Mauro Saccone, Dept. of Architecture, Università Roma Tre, mauro.saccone@uniroma3.it

Antonio Camassa, Dept. of Architecture, Università Roma Tre, antonio.camassa@uniroma3.it 
